INTERNATIONAL JOURNAL OF RESEARCHES IN BIOSCIENCES, AGRICULTURE AND TECHNOLOGY (c) VISHWASHANTI MULTIPURPOSE SOCIETY (Global Peace Multipurpose Society) R. No. MH-659/13(N) www.ijrbat.in

\title{
POLLEN ANALYSIS OF HONEY SAMPLES FROM DIFFERENT GEOGRAPHIC AREA (MARRIGUDAM, SIRKONDA, KOPPELA) OF Tah. SIRONCHA, Dist. GADCHIROLI OF MAHARSHTRA.
}

\author{
Ayesha Hussain Khan \\ Department of Botany, Dr. C.V. Raman Sicence College, Sironcha, Dist. Gadchiroli. \\ Email-ID:ak6765065@gmail.com
}

\begin{abstract}
:
The study represents the pollen contents of 3 honey samples of natural bee hives of Apiscerana indica in summer season collected from the 3 different geographic regions of Tah. Sironcha, Dist. Gadchiroli of Maharashtra. According to qualitative analysis, 3 honey samples were multifloral. Pollen analysis of honey samples, 23 different plants have been determined. The plants contributing nectars and pollens to honey samples in different areas of Tah.Sironcha ,Dist. Gadchiroli were found as fallows; Fabaceae (Pongamia, Butea, Trifolium, Dalbergia, Tamarindus); Asteraceae (Tridax, Helianthus); Apiaceae (Daucus, Coriandrum); Anacardiaceae (Mangifera); Meliaceae (Azadirachta); Mimoceae (Acacia); Myrtaceae (Psidium, Syzgium); Combertaceae (Terminalia arjuna, T. tomentosa, T. chebula); Malvaceae (Abelmoscus); Sapotaceae (Madhuca); Brassicaceae (Brassica); Rutaceae (Citrus); Poaceae (Oryza); Solanaceae (Lycopersicon). The pollen spectra of the samples were indicated various plant species, visiting by honey bees in the area which reflect the vegetation types in the geographical area (Marrigudam, Sirkonda, Koppela) of Tah. Sironcha, Dist. Gadchiroli. And other important taxa as sources of nectars by honey bees were also identified and listed. The numerous pollen types and their diversity showed that bees travel considerable distance collecting nectar and pollen for honey production.
\end{abstract}

Keywords: Honey, Pollen diversity, Pollen analysis, Apiscerana indica.

\section{INTRODUCTION:}

Melittopalynology is one of the applied branches of Palynology that deals with the study of pollen in the honey. The term Melittopaynology is derived from the Greek words Melitta and Melissa (the Attic form)meaning "a bee" as well as honey (in Homer). The Latin word mel (mellis) also means honey. Though the International Commission for Bee Research prefers the term Melissopalynology involving the study of pollen in honey.

Bee forage includes nectar and pollen nectar is the basic raw material from which honey bees make honey, whereas pollen rich in Amino acids, Carbohydrates, Vitamins and hormones as an essential ingredient for bee nutrition and development of the brood and is therefore essential for the maintenance of a healthy bee colony. Pollen analysis of honey and bee collected pollen loads for their pollen content provide valuable information regarding plant preferred by the bees for nectar / pollen or both nectar and pollen. It further reflects upon the characteristic local flora and vegetation assemblage of the area studied. It also furnishes information on major and minor sources of nectar and pollen and helps identifying area with possibilities of having for commercial honey production.
The present research work made on honey bee pollen loads of Marrigudam, Sirkonda and Koppela areas of Tah. Sironcha, Dist. Gadchiroli of Maharashtra. The region is potentially covered with medium sized trees and shrubs which constitute the woody component of the forest. They includes Tectona grandis, Madhuca indica, Terminalia sp., Mangifera indica, Acacia nilotica, Pongamia piñata, Syzygium cumini, etc. are widely distributed along the agriculture tracks. The major cultivated crops and vegetables are Oryza sativa, Helianthus annus, Daucuscarota, Lycopersicum sp., Brassica sp. considerably grown in this regions. The area is also covered with several weeds and grasses.

\section{METHOD AND MATERIAL:}

In the present melittopalynological study, three samples of honey were collected during the summer season from different location of Tah. Sironcha. All honey samples were collected from the natural Apiscerena indica hives. Honey combs were squeezed to remove the honey and only the honey storage portion of comb was used. 50 to $100 \mathrm{gm}$ of honey was collected from each hive and brought in the laboratory for the pollen analysis. The acetolysis method adopted by Erdtman (1960) was used for this study. After centrifugation, the supernatant liquid was decanted off. The pollen sediments was taken on a pallet of glycerin jelly and transferred to 
the centre of the slides. After being warmed slightly the melted jelly with pollen sediment was covered by cover slip and sealed it with paraffin wax (Nair, 1960). These slides of pollen observed under the microscope. For the identification of pollen.

Following are the recommendations of International Commission for Bee Botany (ICBB, 1970), samples with $45 \%$ or more pollen of a single type are termed as 'unifloral'. The terminology used for describing pollen morphology is based on that of Erdtman et al. (1961) and modified by Nair (1970). For the presentation of frequencies of pollen grains in honey, the system adopted by Louveaux et al. (1978) was used.

Observations:

Tah.Sironcha of vegetation includes moderate size Trees, Shrubs and Herbs occur in forest with agricultural tracks. In melittopalynological studies, three honey samples collected during honey flow period May to June 2017. The colour of the honey sample is light amber. On the basis of frequency distribution of pollen type in honey, all three samples are multifloral. There are twenty three plant species of different families shows their appearance in the collected honey samples of Apiscerana indica. The illustrate plant species in Table - 1 regarded as a source of nectar and pollen to honey bee in the summer period of this regions.

\section{RESULT AND DISCUSSION:}

After the analysis of pollen load, the appearances of plant species that are Fabaceae: Pongamia, Trifolium, Butea, Dalbergia, Tamarindus; Asteraceae:Tridax, Helianthus; Apiaceae: Daucus, Coriandrum; Anacardiaceae: Mangifera; Meliaceae: Azadirechta; Mimoseae: Acacia; Myrtaceae: Psidium, Syzygium: Combretaceae:Terminalia; Malvaceae: Abulmoscus; Sapotaceae:Madhuca; Brassicaceae: Brassica; Rutaceae: Citrus; Poaceae: Oryza; Solanaceae:Lycopersicon representing the main major pollen source for Apiscerana indica in the region of Tah. Sironcha, Dist. Gadchiroli.

The region of investigation is mainly tropical where the flowering plants, trees, shrubs and herbs are profusely distributed along with agricultural fields. The region selected for investigation has good potential for sustaining beekeeping venture because of nectar and pollen. The honey obtained during summer period is of high quality and has high commercial potential.

\section{CONCLUSION:}

Although a relatively vigorous understanding of the major genera within Solanaceae exists, it is interested to note that if the sample population is more then phylogenetic inference was found to be poor. As indicated by present investigation after utilizing non-coding trnL-F data, it generate advocacy towards the utilization of this region to discriminate the species under same genus. Moreover, combined data set from coding and noncoding regions of species can also provide robust analysis for separation of closely related species as well as varieties.

\section{REFERANCE :}

Anklam E. (1998) review of the analytical methods of determine the geographical \& Botanical origins of honey. Food Chem.63, 549-562.

Bhusari, N.V., Mate, D.M. and Makde, K.H. 2005. Pollen of Apis honey from Maharashtra.Grana 44: 216-224.

Erdtman, G. 1960. The acetolysis method.A revised description.Sv. Bot. Tidskr, 54: 561-564.

Erdtman, G., B. Berglund and J. Praglowski. 1961. An introduction to a Scandinavian Pollen flora. Grana Palynologica. 2(3): 3-92.

Ghugal.S.I., Rahile B.S. and Bramhankar K.B.2015. Pollen Analysis of Honey from Different Geographic area of Bhandara Dist.of Maharashtra.

International Commission for Bee Botany (ICBB). 1970. Methods of melissopalynology. Bee World. 51: 125-138.

Louveaux,J., Maurizio,A. and Vorwohl,G. 1978. Methods of melissopalynology. Bee World 59: 139-157.

Molan P.C. (1998) The limitations of the methods of identifying the floral sources of honey,Bees World 79,59-68.

Phadke, R.P. 1967. Studies on Indian Honey. Proximate composition and physicochemicalCharacteristic of Indian multifloral apiary honey from Apisindica bees. Ind. Bee J. 29: 14-26.

Sen, J. and Banerjee, D. 1956. A pollen analysis of Indian honey. Bee World 37: 5254.Seethalakshmi, $\quad$ T.S. 1983. Melittopalynological investigations on some Indian honeys.In:Proc 2nd Int. conf. Apic. Trop. Climates, New Delhi1980 (ed.Org.Comm.).pp. 609-621. IARI,New Delhi. 
Table-1: Frequency distribution of pollen type in summer honey of Apisceranaindica Collected from different areas of Tah. Sironcha.

\begin{tabular}{|c|c|c|c|c|}
\hline Sr.No. & Plant species & Marrigudam & Sirkonda & Koppela \\
\hline 1. & Mangifera indica & 4.72 & 3.1 & 2.24 \\
\hline 2. & Corandrum sativum & 1.27 & --- & 3.45 \\
\hline 3. & Doucus carota & 2.54 & 2.24 & 4.22 \\
\hline 4. & Pongamia pinnata & 3.46 & --- & 3.1 \\
\hline 5. & Butea monosperma & 3.05 & 2.6 & --- \\
\hline 6. & Azadirachta indica & 2.4 & 3.1 & 2.24 \\
\hline 7. & Acacia nilotica & 3.46 & 1.27 & 2.45 \\
\hline 8. & Dalbergia sissoo & 4.05 & 3.05 & 4.62 \\
\hline 9. & Psidium guajava & 2.69 & 4.6 & 5.6 \\
\hline 10. & Tamariandus indica & 3.38 & 2.67 & 3.1 \\
\hline 11. & Syzgium cumini & 2.89 & 3.84 & 5.67 \\
\hline 12. & Terminalia arjuna & 3.61 & 4.25 & 3.57 \\
\hline 13. & Terminalia tomentosa & 2.54 & 3.47 & 2.5 \\
\hline 14. & Terminalia chebulla & 3.67 & 3.5 & --- \\
\hline 15. & Abelmoscus sp. & 2.82 & 3.64 & 2.80 \\
\hline 16. & Madhuca sp. & 2.82 & 3.64 & 2.80 \\
\hline 17. & Brassica sp. & 3.52 & 4.3 & 5.69 \\
\hline 18. & Trifolium sp. & 3.55 & 4.5 & --- \\
\hline 19. & Citrus sp. & ---- & --- & 3.23 \\
\hline 20. & Helianthus annus & 3.57 & 3.3 & 3.45 \\
\hline 21. & Tridax procumbens & 4.5 & 3.45 & 4.54 \\
\hline 22. & Oryza sativa & --- & 4.67 & 2.82 \\
\hline 23. & Lycopersicon esculentus & 3.2 & 3.69 & 2.42 \\
\hline
\end{tabular}

\section{Frequecy distribution of pollen type in honey different area of Sironcha}

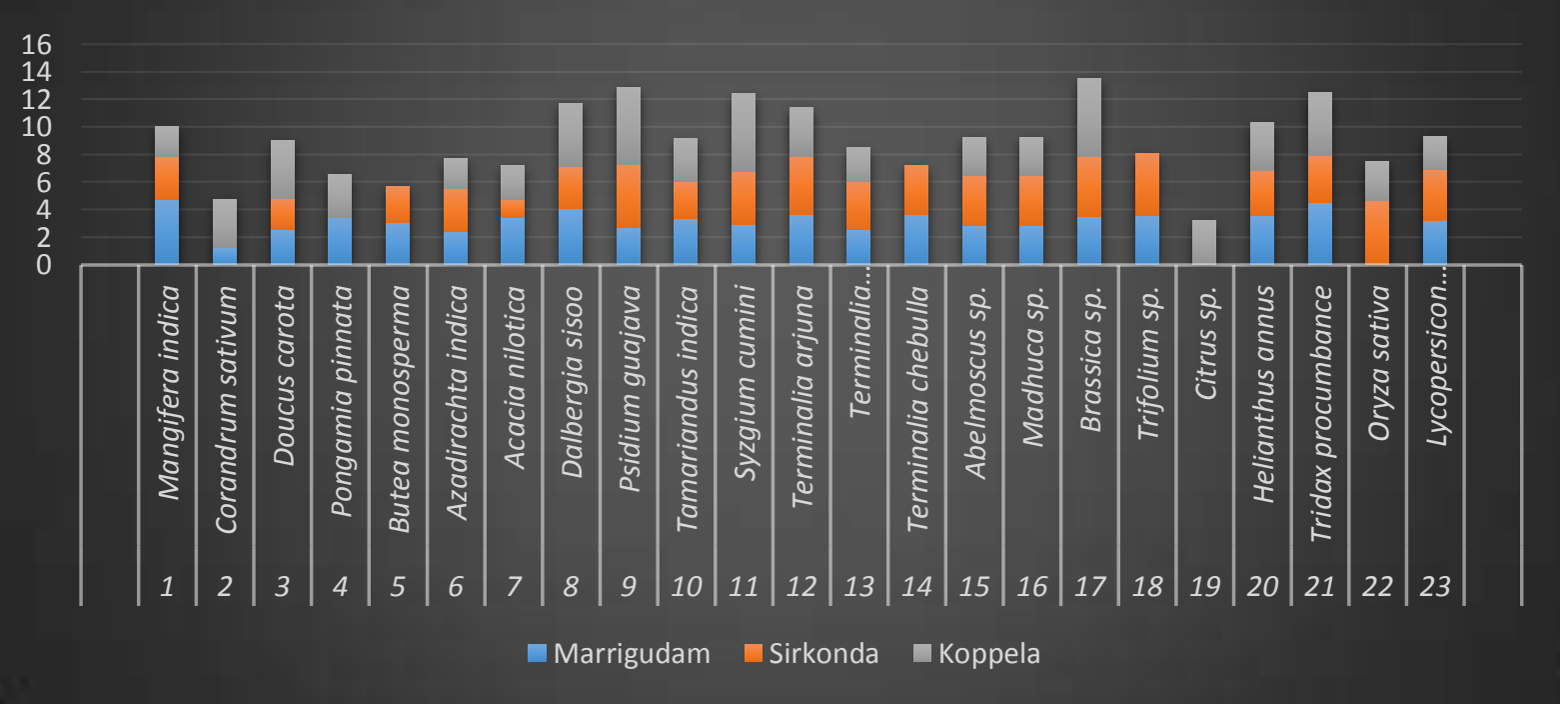

Graph: Shows frequency distribution of pollen type in summer honey of Apiscerana indica collected from different areas (Marrigudam, Sirkonda, Koppela) of Tah. Sironcha. 